\title{
Hyponatremic Chloride-depletion Metabolic Alkalosis Successfully Treated with High Cation-gap Amino Acid
}

\author{
Akihiro Ryuge ${ }^{1,2}$, Katsuomi Matsui ${ }^{1}$ and Yugo Shibagaki ${ }^{1}$
}

\begin{abstract}
Chloride (Cl)-depletion alkalosis (CDA) develops due to the loss of Cl-rich body fluid, i.e., vomiting or diuretics use, and is typically treated with a chloride-rich solution such as normal saline (NS). Although NS is one of the most utilized Cl-rich solutions, high cation-gap amino acid (HCG-AA) predominantly comprises $\mathrm{Cl}$ and less sodium, making HCG-AA more efficient in correcting CDA. We herein report a case of CDA with chronic hyponatremia after frequent vomiting, which was successfully treated with HCG-AA without overcorrecting hyponatremia or causing hypervolemia. HCG-AA may be more beneficial than NS for treating hyponatremic or hypervolemic metabolic alkalosis.
\end{abstract}

Key words: metabolic alkalosis, chloride depletion, hyponatremia, treatment, high cation-gap amino acid

(Intern Med 55: 1765-1767, 2016)

(DOI: 10.2169/internalmedicine.55.6356)

\begin{abstract}
Introduction
Recently, it has been emphasized that the depletion of chloride $(\mathrm{Cl})$ rather than the volume itself plays a major role in developing and maintaining metabolic alkalosis (1). Although normal saline (NS) is recommended to treat Cldepletion alkalosis (CDA) (2), it can cause overcorrection of hyponatremia and/or volume overload, both of which make its use inappropriate in patients with severe chronic hyponatremia and/or volume overload (3). Theoretically, high cation-gap amino acid (HCG-AA) rich in branched-chain AAs, with a $\mathrm{Cl}$ concentration that is higher than its sodium (Na) concentration, should be more efficient than NS in treating CDA as it requires less volume of the solution, leading to a lower risk of overcorrecting hyponatremia or volume overload. However, to the best of our knowledge, no cases have reported the use of HCG-AA in treating CDA. We herein report a case of CDA, complicated with hyponatremia and hypokalemia after frequent vomiting, which was successfully treated with HCG-AA without overcorrecting hyponatremia.
\end{abstract}

\begin{tabular}{l} 
Case Report \\
\hline A 29-year-old pregnant woman ( 23 gestational weeks) \\
with a history of alcoholism, personality disorder, and bipo- \\
lar disorder presented to our hospital with a history of vom- \\
iting 30 times since the previous day. She was urgently ad- \\
mitted to the intensive care unit because the laboratory data \\
showed severe CDA, hyponatremia, and hypokalemia with \\
ECG showing a prolonged QT interval. \\
On admission, her height and body weight were $157 \mathrm{~cm}$ \\
and $44.3 \mathrm{~kg}(\mathrm{BMI} 18$ ), respectively. Her blood pressure was \\
132/71 mmHg, heart rate was $90 /$ min, and body temperature \\
was $36.9^{\circ} \mathrm{C}$. Physical findings were unremarkable in the re- \\
gion of the head, neck, chest, or abdomen, and no abnormal \\
neurological findings were observed. A venous blood gas \\
analysis showed pH of 7.556, pCO ${ }_{2}$ of 64.4 mmHg, and bi- \\
carbonate of 57.1 mmol/L. The laboratory data were as fol- \\
lows: Na, $120 \mathrm{mEq} / \mathrm{L}$; potassium (K), 2.6 mEq/L; $\mathrm{Cl},<50$ \\
mEq/L; serum urea nitrogen, 22.6 mg/dL; creatinine, 1.69 \\
mg/dL; estimated glomerular filtration rate (eGFR) of 30.7 \\
mL/min/1.73 m²; and serum osmolality; $244 \mathrm{mOsm} / \mathrm{kgH} \mathrm{H}_{2} \mathrm{O}$. \\
An electrocardiogram showed a QTc interval of 0.577 sec \\
[reference value: $0.36-0.44$ sec]. A urine electrolyte analysis
\end{tabular}

\section{Case Report}

A 29-year-old pregnant woman (23 gestational weeks) with a history of alcoholism, personality disorder, and bipolar disorder presented to our hospital with a history of vomiting 30 times since the previous day. She was urgently admitted to the intensive care unit because the laboratory data showed severe CDA, hyponatremia, and hypokalemia with ECG showing a prolonged QT interval.

On admission, her height and body weight were $157 \mathrm{~cm}$ and $44.3 \mathrm{~kg}$ (BMI 18), respectively. Her blood pressure was $132 / 71 \mathrm{mmHg}$, heart rate was $90 / \mathrm{min}$, and body temperature was $36.9^{\circ} \mathrm{C}$. Physical findings were unremarkable in the region of the head, neck, chest, or abdomen, and no abnormal neurological findings were observed. A venous blood gas analysis showed $\mathrm{pH}$ of $7.556, \mathrm{pCO}_{2}$ of $64.4 \mathrm{mmHg}$, and bicarbonate of $57.1 \mathrm{mmol} / \mathrm{L}$. The laboratory data were as follows: $\mathrm{Na}, 120 \mathrm{mEq} / \mathrm{L}$; potassium $(\mathrm{K}), 2.6 \mathrm{mEq} / \mathrm{L} ; \mathrm{Cl},<50$ $\mathrm{mEq} / \mathrm{L}$; serum urea nitrogen, $22.6 \mathrm{mg} / \mathrm{dL}$; creatinine, 1.69 $\mathrm{mg} / \mathrm{dL}$; estimated glomerular filtration rate (eGFR) of 30.7 An electrocardiogram showed a QTc interval of $0.577 \mathrm{sec}$ [reference value: $0.36-0.44 \mathrm{sec}$. A urine electrolyte analysis

${ }^{1}$ Department of Nephrology and Hypertension, St. Marianna University School of Medicine, Japan and ${ }^{2}$ Department of Nephrology, ChubuRosai Hospital, Japan

Received for publication August 11, 2015; Accepted for publication September 27, 2015

Correspondence to Dr. Akihiro Ryuge, ryuge0120@yahoo.co.jp 


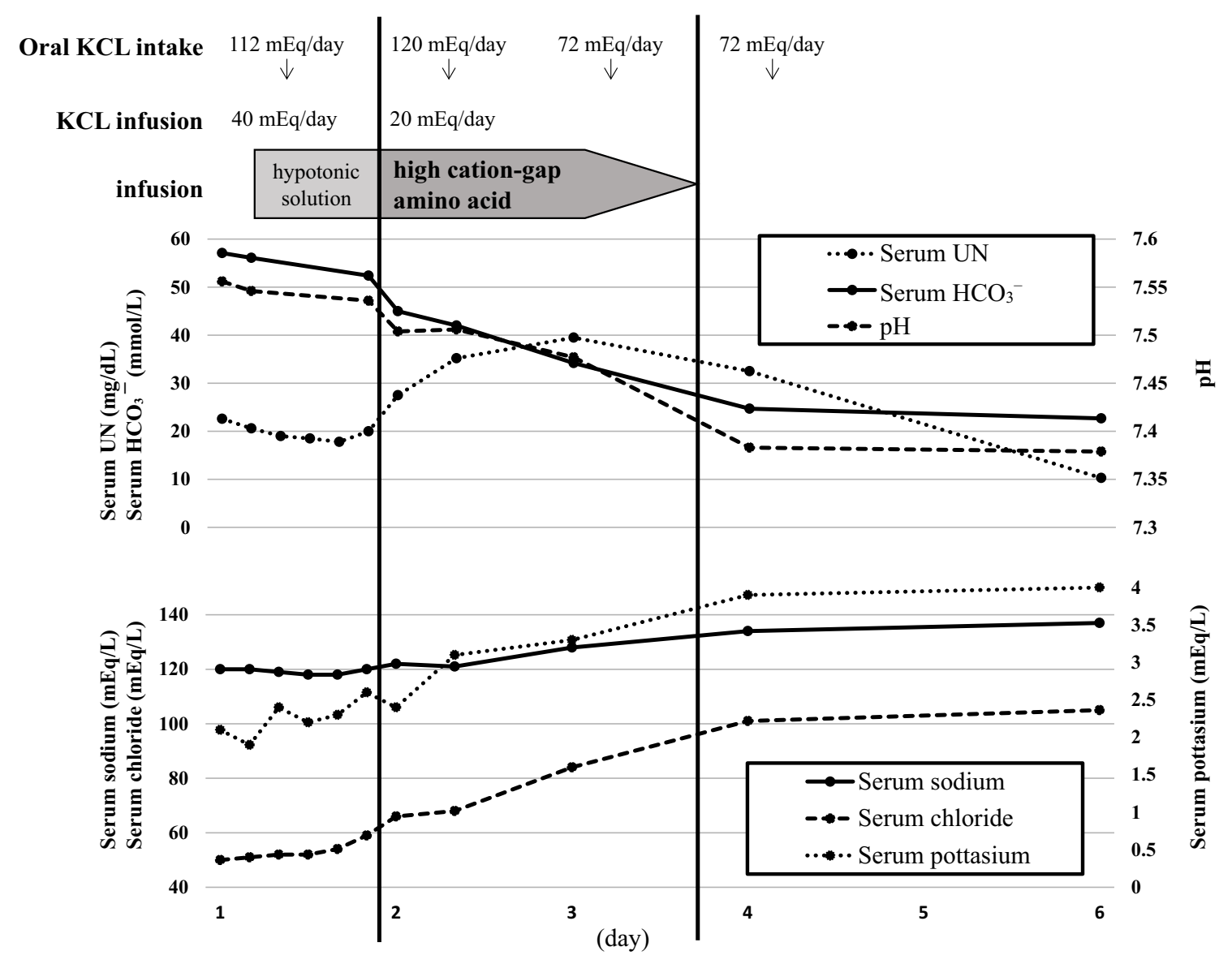

Figure. Clinical course of the patient

showed the following: Na, $48 \mathrm{mEq} / \mathrm{L} ; \mathrm{K}, 23.2 \mathrm{mEq} / \mathrm{L} ; \mathrm{Cl}, 8$ $\mathrm{mEq} / \mathrm{L}$; creatinine, $38.9 \mathrm{mg} / \mathrm{dL}$; urea nitrogen, $151 \mathrm{mg} / \mathrm{dL}$; and osmolality, $200 \mathrm{mOsm} / \mathrm{kgH}_{2} \mathrm{O}$. Although her inferior vena cava diameter was $13 / 9 \mathrm{~mm}$ by ultrasonography, respiratory variation in the arterial pressure waveform in A-line existed. A thorough history taking revealed that she had presented to another hospital with toxic alcohol poisoning. The data at the time showed the following: $\mathrm{Na}, 129 \mathrm{mEq} / \mathrm{L} ; \mathrm{K}$, $2.4 \mathrm{mEq} / \mathrm{L} ; \mathrm{Cl}, 64 \mathrm{mEq} / \mathrm{L}$; serum urea nitrogen, $20.4 \mathrm{mg} /$ $\mathrm{dL}$; creatinine, $1.05 \mathrm{mg} / \mathrm{dL}$; and eGFR of $51.7 \mathrm{~mL} / \mathrm{min} / 1.73$ $\mathrm{m}^{2}$.

Severe metabolic alkalosis with volume depleted chronic hyponatremia as a result of hydrogen ion and $\mathrm{Cl}$ loss from vomiting was diagnosed according to the abovementioned findings, and we initially treated the patient's hypokalemia with oral potassium chloride $(\mathrm{KCl})$ and administered a hypotonic solution (composition of this solution was $\mathrm{Na}, 33.7$ $\mathrm{mEq} / \mathrm{L} ; \mathrm{K}, 38.5 \mathrm{mEq} / \mathrm{L}$; and $\mathrm{Cl}, 33.7 \mathrm{mEq} / \mathrm{L}$ ), which did not improve the situation (Figure). Although renal replacement therapy such as dialysis might be a choice for treatment, we did not select this method due to its invasiveness and because it could lead to hyponatremia overcorrection by dialysate diffusion. We attributed the cause of this relative unresponsiveness to concurrent metabolic alkalosis (4), which led us to add a $\mathrm{Cl}$ supplement. Because we were afraid to use NS for potential rapid overcorrection of hyponatremia, we initially administered $500 \mathrm{~mL}$ of HCG-AA (Terufis,
TERUMO, Tokyo, Japan) by adding $20 \mathrm{~mL}$ of $10 \% \mathrm{NaCl}$ and $50 \mathrm{~mL}$ of a $\mathrm{KCl} 20 \mathrm{mEq}$ injection kit, whose composition was $\mathrm{Na}, 71.9 \mathrm{mEq} / \mathrm{L} ; \mathrm{K}, 35.1 \mathrm{mEq} / \mathrm{L}$; and $\mathrm{Cl}, 177.2$ $\mathrm{mEq} / \mathrm{L}$, at rate of $60 \mathrm{~mL} / \mathrm{hr}$ in addition to oral $\mathrm{KCl}$. After the administration of this solution, the patient's metabolic alkalosis and hypokalemia quickly improved without overcorrection of hyponatremia (Figure). The day after admission, her QT interval improved to the normal range, and she was allowed to leave the intensive care unit. After confirming the improvement of the patient's metabolic problems, the rate of this solution was gradually decreased and finally discontinued on day 3 (Figure). Seven days after her admission, the patient was discharged.

\section{Discussion}

The present case demonstrated that we can treat CDA effectively with HCG-AA. To the best of our knowledge, this is the first case report to show the efficacy of HCG-AA in treating CDA.

HCG-AA, which is abundant in branched-chain AA, is expected to improve hepatic encephalopathy (5). On the other hand, it has a unique characteristic in that it contains much more $\mathrm{Cl}$ than $\mathrm{Na}\left(\mathrm{Na}^{+}: 14 \mathrm{mEq} / \mathrm{L}\right.$ vs. $\left.\mathrm{Cl}: 94 \mathrm{mEq} / \mathrm{L}\right)$, which is referred to as a high "cation-gap." Because $\mathrm{Cl}$ depletion rather than $\mathrm{Na}$ or volume depletion is more important in developing and maintaining metabolic alkalosis, it is 
reasonable to administer Cl-rich high cation-gap AA. Moreover, according to the physicochemical approach suggested by Stewart, a strong ion difference (SID), which is calculated as $\left[\mathrm{Na}^{+}\right]+\left[\mathrm{K}^{+}\right]+\left[\mathrm{Ca}^{2+}\right]+\left[\mathrm{Mg}^{2+}\right]-\left[\mathrm{Cl}^{-}\right]$, is thought to be a determinant factor for acid-base disturbance (6). The normal range of SID is nearly $40 \mathrm{mEq} / \mathrm{L}$ and when a patient is administered a fluid infusion with a SID less than $40 \mathrm{mEq} / \mathrm{L}$, he will develop strong ion acidosis. Because it is important to decrease the SID in treating alkalosis, theoretically speaking, high cation-gap AA with a more negative SID should be more efficacious than NS, the SID of which is zero $(1,6)$. If HCG-AA is more effective than NS to treat CDA, then one may also administer less volume of the solution of HCG-AA compared to NS.

There are two main advantages for administering a lower volume in the treatment of metabolic alkalosis.

First, a lower volume of fluid is better in the treatment of CDA complicated with volume overload, in particular because CDA often occurs in patients with volume overload due to the use of loop or thiazide diuretics. It is especially difficult to use NS in patients with volume overload such as those with heart failure, and HCG-AA is theoretically a preferable solution to treat such patients.

Second, a decreased volume of fluid administration makes it possible to avoid overcorrecting hyponatremia. Because HCG-AA contains a decreased amount of $\mathrm{Na}$ (and less $\mathrm{Cl}$ ) compared to NS, it has a much lower risk of overcorrecting the serum $\mathrm{Na}$ concentration because it has a lower risk of suppressing volume dependent anti-diuretic hormone (ADH) secretion. As shown in the present case, the Na concentration was not rapidly corrected by using HCG-AA.

When using HCG-AA, care should be taken because it contains a substantial amount of nitrogen, which can lead to a high blood urea nitrogen concentration and/or ureaosmotic diuresis (7), thereby resulting in overcorrection of hyponatremia, especially in patients with a low GFR. We should pay special attention to the risk of raising the blood urea nitrogen level due to HCG-AA, especially when we treat patients with renal failure. According to Figure, the present patient's serum urea nitrogen concentration increased during HCG-AA therapy. Fortunately, judging from the urine urea concentration, our case did not present with urea osmotic diuresis, which is thought to be present if the urea concentration in the urine exceeds $250 \mathrm{mmol} / \mathrm{L}$ (7). Another potential limitation is that the sodium concentration of
HCG-AA is low, which may aggravate hyponatremia. Thus, when we treat CDA with chronic hyponatremia, we should be aware of these potential complications.

In the present case, the patient's electrocardiogram showed a prolonged QT interval which could be lethal, and we initiated immediate treatment for her hypokalemia and metabolic alkalosis. Following the administration of HCGAA, all the patient's metabolic problems resolved quickly. However, as seen in Figure, the patient's metabolic problems were gradually resolving prior to the administration of HCG-AA. It is possible that in this case, continued supplementation with $\mathrm{KCl}$ and the judicious use of a hypotonic $\mathrm{NaCl}$ solution could have eventually led to a resolution over a longer period of time. However, as this case shows, HCGAA clearly showed an advantage to NS, thus which patients are indicated for HCG-AA treatment of CDA should be clarified in future studies.

In conclusion, we can successfully treat hyponatremic CDA with HCG-AA. HCG-AA should be considered for the treatment of metabolic alkalosis with severe chronic hyponatremia and/or volume overload, in which we may hesitate to use NS.

\section{The authors state that they have no Conflict of Interest (COI).}

\section{Acknowledgement}

We express our sincere thanks to Dr. Virginia L. Hood for giving us constructive comments and encouragement.

\section{References}

1. Luke RG, Galla JH. It is chloride depletion alkalosis, not contraction alkalosis. J Am Soc Nephrol 23: 204-207, 2012.

2. Galla JH. Metabolic alkalosis. J Am Soc Nephrol 11: 369-375, 2000.

3. Lin SH, Chau T, Wu CC, Yang SS. Osmotic demyelination syndrome after correction of chronic hyponatremia with normal saline. Am J Med Sci 323: 259-262, 2002.

4. Aronson PS, Giebisch G. Effects of pH on potassium: new explanations for old observations. J Am Soc Nephrol 22: 1981-1989, 2011.

5. Naylor CD, O'Rourke K, Detsky AS, Baker JP. Parenteral nutrition with branched-chain amino acids in hepatic encephalopathy. A meta-analysis. Gastroenterology 97: 1033-1042, 1989.

6. Seifter JL. Integration of acid-base and electrolyte disorders. N Engl J Med 371: 1821-1831, 2014.

7. Lindner G, Schwarz C, Funk GC. Osmotic diuresis due to urea as the cause of hypernatraemia in critically ill patients. Nephrol Dial Transplant 27: 962-967, 2012.

(C) 2016 The Japanese Society of Internal Medicine http://www.naika.or.jp/imonline/index.html 